\title{
Market Building through Regional Integration Agreements \\ : The EU and the ASEAN Way
}

Gabriele Orcalli

University of Padova, Padova, Italy

\begin{abstract}
We define the internal market of a regional integration agreement as a legal order that is based on the rule of law. A regional integration agreement is a particular case of market building in that it creates a new market with new rules. The ability to change the participating institutions is essential. A key issue consists in verifying that a constitutional change is possible as well as adapting the local institutions to the new constitution. In comparing the case of the European Union and the Association of Southeast Asian Nations, we rely on the assumption that a shared goal can be achieved with different solutions that consider the starting point of participating states. In terms of the Association of Southeast Asian Nations, we consider the possible absence of centralized powers.
\end{abstract}

\section{JEL Classifications: F15, F55}

Keywords: Regional Integration, Market Building, Rule of Law, Constitution, ASEAN Way, European Union

\footnotetext{
* Corresponding Author: Gabriele Orcalli; University of Padova, Department of Economics and Management, via del Santo 33, 35123 Padova, Italy, Tel: +398274218, E-mail: gabriele.orcalli@unipd.it

Acknowledgements: This work was supported by University of Padova research funds. The author would like to thank Prof. Maurizio Mistri, Prof. Philomena Murray and an anonymous referee for their extensive comments.
} 


\section{Introduction}

Studies of regionalism have grown incrementally in recent decades and consist largely of comparative analyses of the origins and sustainability in the formation of economic communities and internal markets. Many of these analyses tend to focus on regional market building, particularly the architectural design of such markets, as part of regional bodies.

An important distinction that needs to be made is between the concept of market liberalization (shallow integration), which can refer to a multilateral agreement or a free trade area, and that of deep integration, namely, the replacement of national markets with a new single market. For example, the European Union (EU) refers to this when referring to a single market defined by the Single European Act as a "market without frontiers." The crucial difference is that deep integration requires not only overcoming the problem of nontariff and tariff barriers, but also defining a new system of law and order for establishing rules and their enforcement, i.e., a constitutional change.

A regional integration agreement (RIA henceforth) is a particular case of market construction in that it creates a new market or a new organization with new economic transaction rules. For this reason, the ability to change the participating institutions is essential. As will be seen, a key issue is the ability to verify that a constitutional change is possible and the subsequent adaptation of local institutions to the new constitutional rules.

In this paper, we seek to understand in a comparative context the design features that characterize an internal market. The EU's experience has at times been regarded as a template for other regional bodies throughout the world, and this has often hampered the comparative analysis of the formation of internal markets by confusing the study of European integration with the study of economic regionalism, which is itself a subset of the broader study of European integration. In other words, in a Eurocentric view, the EU is often considered to be the universal model for the construction of a domestic market, where success (or failure) of other RIAs is measured by their proximity to (or remoteness from) the European model.

Indeed, much scholarly literature on international cooperation focuses on regional agreements that are characterized by a single efficient solution to the problems of the interaction of states as less than sufficient (for example, Garrett and Weingast 1993). Functional approaches that are based solely on identifying the most efficient solution or 
assessing the national interests of states cannot, however, provide valid explanations for international cooperation applied in a comparative context across regions. Even though these types of analyses can confirm ex post whether the solutions identified are efficient, they cannot explain why these particular solutions were chosen.

Garrett (1992) notes that many empirical studies indicate that there may be many different solutions to the need for interstate cooperation in a regional body and that none can be considered as having general validity. These studies can thus be synthesized with the "folk theorem" in noncooperative game theory, which emphasizes that in repeated games with non-superficial information, infinite solutions can be sustained in equilibrium, including those not on the Pareto-optimal frontier (Weingast 1997) ${ }^{1}$. This implies that the assessment of cooperative solutions to a problem, such as the construction of an internal market, requires considering not only one optimal solution, but a number of possible solutions. Further, in the search for, and selection of, a common solution, neither the impact of redistributive power and asymmetries nor the importance of ideas, social norms, institutions, and shared expectations can be overstated (Garrett and Weingast 1993, Murray and Warleigh-Lack 2013).

In evaluating the case of the Association of Southeast Asian Nations (ASEAN), this observation enables us to avoid comparisons that are based on the use of the European integration experience as a benchmark. Rather, we rely on the assumption that a shared goal, such as the construction of an internal market, can be achieved with different solutions that consider the starting point of participating states. As Glaeser and Shleifer (2003) underline, different institutions in different circumstances can provide the solution to the perceived need for a single market and the basic issue of market regulation, namely, the protection of property rights. However, recognizing that there may be different solutions to the same problem does not mean that all solutions can be adapted to the established objective.

To examine this issue, we draw upon some analytical tools offered by both political science and economic literature. In particular, we use analyses that define the marketand therefore the internal market of an RIA - as a legal order based on the rule of law. Of course, introducing the concept of rule of law in comparing two fundamentally different political realities, such as those in this paper, cannot but lead to difficulties, and these will be highlighted in the following sections. Indeed, the concept of rule of law was

\footnotetext{
'In game theory, in infinitely repeated games with an intertemporal link between what occurs in a certain period and what will occur in the future, it is possible to show that behaviors that would not be optimal in the short term, could be in the longer term. This was called the Folk Theorem because it was widely known among game theorists in the 1950s, even though no one had published it.
} 
established in the Western world and exported to Asia, particularly during the period of colonialism, and is therefore not part of their cultural traditions. Nevertheless, we jointly consider the two realities in a comparative analysis as there are many authoritative voices in ASEAN that identify precisely the rule of law as the central point of the construction of an internal market. Furthermore, to enable such a comparison between different realities, we adopt Hadfield and Weingast's (2012) proposal, according to which a legal order is not necessarily defined by the presence of a "centralized enforcement body" but can exist - under the conditions that we will highlight — even in the absence of a central government but with the power of enforcement.

In terms of the economic analyses, we draw particularly upon Schelling's (1960) strategy of conflict, which draws attention to the role of shared beliefs as focal points around which the behaviors of economic agents converge, particularly in the construction of constitutions as coordinating devices (Hadfield and Weingast 2014). We further use the Stone, Sweet, and Brunell (1998) approach that examines the formation of internal markets through the role of three causal factors, namely, individual contracting, third party-dispute resolution, and the production of legal norms.

To assess whether an RIA's success or failure depends on the economic constitution chosen by the participating states, we also draw on Glaeser and Shleifer's (2003) analysis of the formation of the regulatory state and the constitutional economics approach that James Buchanan (1990) explains as "... a research program that directs inquiry to the working properties of rules, and institutions within which individuals interact, and the processes through which these rules and institutions are chosen or come into being."

With regard to the economic constitution, we make recourse to the Freiburg School's definition, namely, the inclusive decision taken by a community on the way its economic life is to be ordered (Vanberg 1998).

Considerable scholarly attention has been focused on the EU's economic constitution (Streit and Mussler 1994, Vibert 1995, Buchanan 1996), and this paper draws upon their contributions to comparatively analyze the EU and ASEAN, which aim to create a single market.

In the second section, we set out the main theoretical references that we draw on to define the internal market and to identify the criteria for its construction in a regional integration framework. In particular, we recall the importance of institutions, rules, and relational investments in considering the need for a legal order to identify a market.

In subsequent sections, we compare how the two regional agreements were built. 


\section{Theoretical Background}

Economic theory (in the institutionalist and constitutionalist tradition), political science, and economic sociology have often examined issues related to market building and particularly facilitating economic transactions through making and enforcing rules.

The first problem to be dealt with, particularly when comparing the different experiences of the formation of an internal market, is its definition. Following a traditional formulation, the internal market of an RIA is defined by the verification of the law of one price, which is favored by both the protection of competition policy and the presence of full information for sellers and buyers. From this perspective, the formation of a regional market becomes a simple exercise of deregulation, i.e., eliminating tariff and nontariff barriers and monitoring the compliance of participating states to the commitment.

By contrast, one of the basic arguments of institutionalist theory is that there is a link between politics and markets: a market economy cannot exist in a vacuum (Boettke et al. 2005) but is embedded in a broader set of institutions. Thus, it may include the analysis of institutions, legal foundational documents, norms, and practices.

Markets cannot exist without rules enabling economic transactions: property rights, rules on contracts, product and production process standards, and so on.

The formation of markets thus understood (as exchanges regulated by an institutional system) has been the subject of numerous studies in various social science disciplines.

Beckert $(2009,247)$ sees market exchange as "a form of social interaction that can be explained... only by the institutional structures, social networks, and horizons of meaning within which market actors meet" and considers the task of economic sociology as explaining the terms of coordination, i.e., the possibility of actors aligning "their actions in ways that allow for market exchange to take place" (Beckert 2009, 246). Such a possibility derives from the expectations that can be formed regarding the behavior of the other actors who are considered sufficiently compatible with their material interests and ideals.

Duina (2004), in his analysis of the social construction of the market in the EU, North American Free Trade Agreement (NAFTA), and Mercosur, investigates how markets have been built, considering the ability of participants to share cognitive notions, particularly with respect to property rights. In turn, cognitive notions can be ontological or normative according to whether they define the essential characteristics of the objects 
of activities and economic agents or show whether and how certain situations must be accepted and can be reproduced over time.

Staying within the institutionalist framework, the position of economists drawing on this inspiration is noted, namely, assuming the presence of transaction costs where the market is understood to be "a social arrangement that facilitates repeated exchange among a plurality of parties" (Furubotn and Richter 2003, 284).

Recalling the importance of institutions, rules, and relational investments leads one to consider the need for a legal order as a means of identifying a market. It is, therefore, important to consider Hadfield and Weingast's $(2012,473)$ suggestion that an environment (a market) can be considered to be organized on the basis of a legal order if the following conditions are satisfied:

- There is an identifiable entity (an institution) that deliberately supplies a normative classification scheme that designates some actions as wrongful

- Actors, as a consequence of the classification scheme, forego wrongful actions to a significant extent

In this way, Hadfield and Weingast distinguish systems "in which norms are emergent, arising as a matter of practice from repeated interactions and those in which norms are deliberately articulated and systematically implemented" (idem, 474). This is an important distinction for our purposes as we primarily foresee a system similar to the second type reported by the authors at the center of an RIA internal market. Indeed, the efficiency of an RIA internal market depends on the ability to change the behaviors of economic agents within a reasonable period of time. The gradual adaptation through repeated interactions would impose too long a timeframe, particularly in relation to member states with very different interests and habits.

Economic analyses of the formation of markets tend to recognize that the main task of institutions is the same over time and space, namely, to ensure respect for property rights and to make credible the threat of pursuing those who do not respect them. However, even if the objectives are constant, the appropriate institutions may vary with alternative law-enforcement strategies. Glaeser and Shleifer (2003) provide a framework to understand which institutions are suitable for ensuring these rights under varying circumstances. One approach may be in terms of private, nongovernmental enforcement, which is appropriate when the interaction between the parties is continuous and repetitive. In the case of public enforcement, the alternatives are litigation management 
by the courts of justice or governmental regulation. The authors, in their comparison of different alternatives, emphasize the importance of the initial situation of states, particularly the level of vulnerability to attempts to influence the decisions of the courts or the government, corruption, and intimidation.

Thus, the most relevant aspects for the purposes of our analysis of the construction of an internal market are (a) the initial situation of participating states in terms of the level of law enforcement; (b) the situation not only within states but also in the context of their business relations; and (c) constructing where necessary a new domain of law and order that cannot be separated from the construction of a common institutional regulatory system.

Further important theoretical implications for our investigation can be drawn from constitutional economics. In the words of Brennan and Hamlin (2001), "central to the analysis of constitutional choice is a distinction between the constitutional and inperiod level of decision-making. The latter is choice within rules; the former is choice of the rules. Or, as James Buchanan sometimes puts it, constitutional choice is the choice among constraints in contrast to choice under constraints which is the central preoccupation of ordinary economics." However, neither rules nor constraints should be interpreted narrowly here; the constitutional level of choice is concerned with all those rules, constraints, laws, conventions, customs, and institutional arrangements that jointly constitute social order. Equally, the idea of "choice" is not limited to some explicit, deliberative process but is intended to include a considerably wider range of processes by which social order may emerge from individual decision-making.

A constitution, therefore, specifies the operational criteria of an organization, particularly to resolve any fundamental issues that (inevitably) arise from joint actions, such as the rules governing collective decision-making and distribution problems. These latter problems arise because the action of an organization cannot distinguish among members based on their input, and therefore, outputs of collective actions cannot be proportionally redistributed. This results in a constitutional problem as it gives rise to rules or principles governing distribution. Solutions to these issues relate to the constitution's "quality." The greater the collective action, the greater the need to find efficient solutions to both the decision-making processes and the distribution of joint products.

Here, we embrace the notion that market order is subject to an explicit constitutional choice: the benefits of economic transactions in a market depend on its constitutional structure where the citizens' choice of rules becomes the essence of the constitutional 
problem.

According to this line of reasoning, constitutions can be considered to be "coordinating devices" (Hadfield and Weingast 2014) or as focal points in the sense of Schelling (1960) to help people to coordinate and find the balance between different interests. Hadfield and Weingast consider constitutions to be successful when they allow this balance to be achieved, thus improving the effectiveness of the decentralized mechanisms of rule enforcement. Coordination between different positions can take place through the following two tasks:

- Reducing ambiguity and thus serving as a focal point around which people can coordinate enforcement behavior

- Providing a process of public reasoning that, among other things, extends and adapts the existing rules to the new circumstances.

Hadfield and Weingast's interpretation has significant consequences, namely, it is not always possible to either identify a focal point or construct it. In other words, attempts to build an efficient constitution do not necessarily have to lead to a conclusion. However, Garrett and Weingast (1993) indicate that an institution can play an important role in coordinating behaviors by building a focal point where one does not naturally exist, indicating the required set of specifications on the nature of an agreement and on what is meant by cooperation and noncooperation, and disseminating knowledge in the community. In the absence of this institution, the actors should first recognize the problem and then come to a common understanding of both the problem and the solution, thereby recognizing and punishing the defaulters. An institution can avoid this overly complex mechanism, particularly in the presence of different and conflicting individual interests that could inhibit the emergence of decentralized cooperation. Its role becomes that of creating a common vision (shared belief) on cooperation and default.

The authors summarize their interpretation by emphasizing the significance of three interrelated phenomena in the success of a cooperative agreement: a) gains arising from the cooperation for a significant number of players, b) an idea that expresses these gains, and c) a mechanism designed to transfer the idea into a shared belief system so as to influence the expectations of operators and therefore their behaviors.

Can an RIA be defined in these terms? The agreement that underlies an RIA consists of rules that each member state is (or should be) obliged to comply with. These rules show the members' consensus on sharing some of their economic policy resources- 
the instruments of trade and regulation policy - thus committing themselves to using these resources for the benefit of the organization's common goals and following the procedures established by the agreement itself.

A regional market organization stems from an agreement between countries that may differ, particularly in terms of their legal traditions and preferences. What enables agreement on common rules? Does transplanting the rules of a dominant country solve the problem? Does it entail an evolutionary path of pooling cognitive notions in the sense of Duina (2004)? To our mind, this is the key point of comparisons among different experiences of building a regional market and also the fulcrum for overcoming the Eurocentric perspective. An internal market must be constructed in different ways to reflect the initial conditions of individual states even if points in common remain. In other words, the objective is to build a market governed by a legal order that is recognized by all actors insofar as it is capable of improving the wellbeing of the participants.

The above discussion should also be seen in a dynamic context: the political system should aim to continuously adapt its economic constitution to changes in the environment, keeping abreast of citizens' interests. This is based on the concept of an evolutionary dynamic where the economic constitution is the instrument with which communities adapt to changes in the economic climate. The better the acclimatization, the better the chances the community that adopts the constitution has of succeeding. The success of a community, therefore, depends on the development of its problem-solving capacity: "The efficiency and viability of an economic constitution will depend on its ability to channel the problem-solving efforts of the respective jurisdiction's citizens in socially productive directions" (Vanberg 2001, 48).

Analyzing constitutional economics allows us to frame the fundamental questions related to constitution making. The possibility of building an organization and granting it legitimacy is to be found, according to Vanberg (1994), in the relationship between the contractarian interpretation and the dialog interpretation of an agreement.

According to the contractarian interpretation, individual interests give rise to the constitutional process of rule formation. In our case, these correspond to national interests, and the constitutional agreement becomes a type of contract that defines what is mutually acceptable to each state.

The second interpretation instead refers to a constitutional process that is based on the notion of dialog where an agreement achieves equity by identifying a path that seems beneficial to all members. Equity here is not intended as a compromise between different 
and conflicting interests, nor is it intended as the result of common rules that restrict the operations of participants. However, it is intended as the outcome of a process aimed at identifying what is best for all. This constitutional process is based on knowledge and can ultimately indicate new national interests as a result of unearthing what appears to be objectively correct.

In other words, agreement on a new constitution results from the interrelation between theory and interests: "... we must not forget that both 'the contractarian and the dialogue interpretation' of a constitutional agreement cannot be either separated or opposed to one another in our study of how rules are established" (Vanberg 1994, 174). Vanberg observes that in examining real cases, the two interpretations must be integrated to distinguish between constitutional interests and theories since these represent distinct but fundamental components of constitutional preferences and decisions (Vanberg 1994, 175).

The problem of constitutional change is thus critical in creating an RIA and relates to two different but correlated questions: If there is a strong divergence of interests, does it impede an agreement that is based on common rules? If there is a problem of knowledge, does insufficient common knowledge of the effects of common rules help to reach an agreement? The players in such an agreement will not be inclined towards opportunistic behavior only if there are mutual benefits in terms of payoffs.

For our purposes, let us assume that the payoffs of the countries (denoted by A and B) involved in a system of relationships, whichever they may be, depend in the first instance on the nature of these relationships and therefore on the types of strategies that $\mathrm{A}$ and $\mathrm{B}$ adopt. These strategies are what we synthetically refer to as cooperative or noncooperative or, as it were, opportunistic. Let's assume the simplest case, namely, the removal of trade barriers between two countries. We define a strategy as cooperative when it is aimed at eliminating customs duties between A and B. The governments of $\mathrm{A}$ and $\mathrm{B}$ will move on the basis of the symmetrical distribution hypothesis, which is expressed as the theory of comparative advantage in established economic theory. It follows that an opportunistic strategy would be to maintain existing restrictions on the circulation of goods and services between A and B. In summary, we assume that in the case of opportunistic behavior, the two countries' payoffs are, respectively, a and b, namely, the payoffs of a closed market.

Conversely, let's assume that governments A and B deliberate on the potential of a cooperative strategy. Following the theory of comparative advantage, we assume that cooperation in some way changes the allocation of production factors, thus generating an 
increase in the total product obtainable. We denote with $\pi_{A}$ and $\pi_{B}$ the payoffs expected by A and B, respectively, such that we have (Dixit, Skeath, and Rieley 2009, 695) the following:

$$
\pi_{A}=a+h v \text { and } \pi_{B}=b+k v
$$

where $a$ and $b$ indicate the gross domestic product of A and B in closed market conditions, $v$ indicates the expected added value resulting from a policy of openness to trade, and $h$ and $k$ indicate the generic allocation of quotas of $v$ to the two countries.

Let's assume that between A and B, asymmetries manifest over time and become entrenched in their systemic competitiveness such as to alter the relationship between $h$ and $k$. Dynamically, we assume that A increases its quota $v, h(t)$ and $k(t)$ whereby $d h / d t>d k / d t$. If such a possibility is considered by government $\mathrm{B}$, which in the future would be penalized, it may decide not to open its market to the products of A unless it makes side payments to $\mathrm{B}$. What remains to be seen is what strategy government $\mathrm{A}$ adopts. The case of $\Delta t_{1}$ would be interesting, i.e., at the stage preceding the possible start of any negotiations between A and B, government A decides to keep its borders open, while government B decides to keep them closed. This inhibits the possibility of a division of labor between $\mathrm{A}$ and $\mathrm{B}$, and thus $v=0$. Hence, $\mathrm{A}$ and $\mathrm{B}$ do not necessarily receive the payoffs $(a, b)$ that they would receive if the economies of the two countries were self-sufficient as country A would see its trade balance worsen owing to its open policy, with negative effects on employment. By contrast, B would have the advantage of selling its products to A without having to import goods from that country. It follows that the payoff of A would be equal to $a-c$, where $c$ is the loss of income that A would suffer. Conversely, $c$ corresponds to the increase in income that would accrue to B, namely, $b+c$. Indeed, this would be a situation where the strategic interaction, as represented in the strategy $(\mathrm{D}, \mathrm{D})$, would assume the character of a zero-sum game.

Table 1 summarizes the possible strategies of $\mathrm{A}$ and $\mathrm{B}$ with the relative payoffs. We indicate the strategies as before with $\mathrm{C}$ (denoting the open market policy of each country) and with $\mathrm{D}$ (denoting the closed market policy of each country). 
Table 1. Possible strategies of $A$ and $B$ with relative payoffs

\begin{tabular}{|c|c|c|c|}
\hline \multicolumn{2}{|c|}{ Payoff matrix } & \multicolumn{2}{c|}{ Country A } \\
\cline { 2 - 4 } & C & $(a+h v, b+k v)$ & $(a-c, a+c)$ \\
\hline \multirow{2}{*}{ Country B } & D & $(a+c, a-c)$ & $(a, b)$ \\
\cline { 2 - 4 } & D & D \\
\hline
\end{tabular}

(Note) C and D respectively represent a cooperative strategy and a non-cooperative strategy. The equations in the boxes indicate the payoffs expected as a result of the different strategic choices of A and B.

(Source) Author's own creation.

In the case of integration to form an internal market, the dominant strategy should be $(\mathrm{C}, \mathrm{C})$ because of the strategic constraints posed by the constitutional system. This strategy could become dominant over time if the $h / k$ ratio remains constant. Otherwise, a problem of asymmetry in the distribution of $v$ arises, with the risk of the integration project defaulting.

In the European agreement established by the Treaties of Rome and Maastricht and the European Single Act, this outcome is avoided through the monitoring and sanction mechanisms codified by the constitution and designed to prevent opportunistic behavior.

These issues are important in terms of our analysis of building a regional market through an RIA. Can it be implemented between countries with different constitutional traditions? What consequences will these differences have on the quality of an RIA? Further, is a single market that is based on different constitutional rules from those in Europe possible? In terms of ASEAN, can we consider the possibility of no centralized and coercive powers?

\section{Market Building in the EU}

Following the implications of constitutional economics, we can infer that success in building an internal market depends on the quality of the economic constitution.

Evaluating different solutions to this problem in different constitutional contexts, our 
EU and ASEAN cases, enables a comparative analysis and evaluation of constitutional alternatives that, as Vanberg (1999) suggests, we cannot "circumvent by merely referring to the universal standard of an unhampered market." In other words, the success of an RIA in the construction of an internal market depends on the ability of participating states to choose their constitutional rules through trial and error and not simply through national market liberalization. From this perspective, the absence of a universally valid model of building a domestic market is obvious.

European countries have built an internal market that, according to the aforementioned RIA characteristic, started from preexisting national markets endowed with their own regulations. They, therefore, had to make a constitutional change with new rules and a new polity. Craig (2001) suggests that the term "constitutionalizing" is the most appropriate to indicate the transformation of the EU from an international legal order to a constitutional one.

Hence, the EU is a clear example of building a constitution-based single market as Stone Sweet, and Brunell (1998) suggest, and we must, therefore, consider the three fundamental factors they detail for the construction of a new polity, namely, contracting, dispute resolution, and law-making. Indeed, the constitutionalization of the European integration system would seem to have followed the suggested path: interest in business transactions was a catalyst for the solution to problems related to transaction costs, giving rise to significant social demand for dispute resolution. The latter also highlights the existence of significant problems of collective action requiring common normative solutions.

Trade liberalization and the construction of an internal market through the principle of mutual recognition should be considered to be the focal point - as Schelling put iton which the cooperative game centered and led to European integration.

Indeed, as Garrett and Weingast (1993) note, other solutions for the construction of the internal market could have been chosen and range from the extreme of extensive deregulation to the complete replacement of national rules with common rules. In this case, there is no natural focal point. For various reasons, none of these solutions proved to be suitable to Europe, and thus, through trial and error, a new solution had to be constructed on the principle of mutual recognition. The Court of Justice proved to be the institution that was capable of building a natural focal point where none existed, around which member states could continue their negotiations. These negotiations led to the only possible solution to the conundrum of accommodating the diversity of interests of member states: considering the agreement to be an incomplete contract that delegates 
to an institution (the Court of Justice) the task of applying the general intent to specific cases. In other words, the European internal market is based on the court's role, which is to support and interpret the principle of mutual recognition in any dispute that may arise. This appears to be the focal point that is capable of reconciling the interests of different member states. Recourse to a common set of rules, by contrast, occurs only in cases where it is necessary for the existence of the market.

With reference to the aforementioned Glaeser and Shleifer (2003) approach, the EU has chosen a mixed system of litigation (with the court's fundamental role of managing litigation in specific cases) and regulation, with the latter partly public (the rules related to the fundamental requirements of products) and partly delegated to private institutions.

What has enabled European countries to find this meeting point? According to the conclusions of the analyses of the theory of the legal origins by Djankov et al. (2003), we can consider the EU to be a case where certain conditions exist, such as the following:

- The initial choice was made by the founding nations that all referred, albeit to different degrees, to the civil law tradition, thus showing a natural tendency to intervene in the market through a system of rules.

- The existence of different national legal systems (also in their common reference to civil law) intended to remain in the sphere of national sovereignty. With the principle of mutual recognition proving insufficient, the regulation path was of paramount significance, considering that the repeated use of the courts in disputes would have considerably increased transaction costs and could have led to different interpretations in similar cases. This recalls Glaeser and Shleifer's (2003) references to intermediate law and order systems, and according to Mulligan and Shleifer (2005), the criterion that market regulation requires high initial fixed costs, which can be better amortized over a greater number of disputes that occur when the population is larger.

- The novelty of a European internal market led to the consideration of another aspect that Aghion et al. (2010) highlight, namely, the insufficient level of trust between traders. According to these authors, in societies characterized by a high level of trust, recourse to regulation is infrequent. Indeed, in the case of the European market, owing to its scale and the difference between national market institutions, the operators tend to know each other less well and thus rely less on the regulations of other member states, hence, the preference for a common regulatory mechanism. As noted, the EU's choice has been a system of very 
general rules that mainly indicates the basic requirements that a product must meet and delegates the task of defining the technical requirements to private standardization bodies.

The choice of a legal regime linked to the civil law system nevertheless requires a further guarantee of the stability and transparency of common rules, which can only occur through the creation of the market and a common polity through constitutionalizing the integration process.

It is worth recalling here that the possibility of constitutionalizing the integration process is closely linked to a common vision of the rule of law that, despite different traditions, particularly with reference to the common law of Great Britain, member states synthesize in a generally accepted model. "This should provide a solid theoretical identity for the notion of the 'rule of law,' meant as a normative and institutional structure of a modern state within which the legal system ... is entrusted with the task of guaranteeing individual rights, curbing the natural tendency of political power to expand and act arbitrarily" (Zolo 2007). In other words, supporting the rule of law in the construction of the European market implies invoking the protection of individual rights as the main task of political institutions and European legal entities.

The tendency to constitutionalize treaties or to provide a supranational legal reference to protect the interests of citizens, and in any case in all private and public European legal entities, thus overcoming the intergovernmental phase (in which national governments are solely responsible for the implementation of the treaties), was based on an evolution driven by the European Court of Justice, particularly through the principle of supremacy of European norms (introduced with the 1964 Costa judgment) and the principle of direct effects (the 1963 Van Gend and Loos judgment) under which European norms produce legal rights for individuals that must be guaranteed by national courts. In this way, the European directives system became immediately effective. These two principles triggered a constitutional process that allowed traders to use European norms to obtain results that could hardly have been achieved through political governance processes. Finally, Stone, Sweet, and Brunell (1998) indicate that this constitutional process occurred without the explicit consent of national governments, which could only have opposed the process by changing the treaties, a process that requires unanimity. The Court of Justice also appears to have taken on the institutional role that Garrett and Weingast (1993) identified, namely, an institution capable of playing a key role in coordinating the behaviors of actors, in this case both public and private. 
The evolutionary view of the formation of the European market depends strictly on the construction of ties among the three integration factors highlighted by Stone, Sweet, and Brunell (1998), and this in turn depends on the quality of the constitutional requirements established by the founding treaties. It is worth highlighting here the importance of Article 177 of the Treaty of Rome, namely, the possibility or obligation of the courts to refer controversial cases to the European Court of Justice for an authentic interpretation of community rules. This article was clearly aimed at promoting the uniform and consistent application of European norms throughout the EU and was essential in affirming the EU as a unique constitutional polity. Moreover, as previously indicated, international agreements can be treated as incomplete contracts, which means that they can determine disputes on the correspondence between a concrete situation and a rule foreseen by the agreement with respect to the possible violation of a rule by a member state.

These situations are addressed by a dispute resolution system, and it is essential for the sustainability of the agreement that private operators are satisfied with the operation of this system. The solution that the EU found is characterized by the ability of individuals to indirectly access the European Court of Justice through the law courts, which is contrary to what occurs in most international agreements where access to dispute resolution systems is reserved for governments.

The internal market is thus at the foundation of European integration, with high levels of protection of individual economic rights and freedom of trade supported by EU competition policy and the rules of nondiscrimination. The Court of Justice has also greatly strengthened this system through its role as interpreter of the Treaty, affirming the principle of direct effect of the rules of negative integration and attributing them priority over national rules and policies; thus, moving from a type of intergovernmental agreement to a real economic constitution.

The direct effect and supremacy of European rules as well as the principle of mutual recognition are, therefore, the cornerstones of the European constitution with the creation and subsequently the functioning of the internal market at the core of the European mission (De Burca 2003). The EU constitutional structure has developed from this core idea on the basis of the fundamental objective of the internal market and a series of complementary and functional policies on competition, agriculture, and trade.

The constitutionalization of the European integration process has not been without technical and political difficulties. Indeed, the evolution of the principle of mutual recognition has been challenging to put into practice. Economic operators have 
repeatedly stated that the costs of applying this principle diminish its advantages. Pelkmans (2012) distinguishes these costs as information, transaction, and compliance costs and their presence in Vanberg's (1999) trial and error approach gave rise to a regulation (regulation no.765 of 2008 and decision no.769 of 2008) approved by the European Council, the purpose of which was precisely to overcome the technical difficulties linked to the practical use of the principle by businesses.

The political difficulties, however, were widely expected. The constitutional economics analyses indicate that a constitution results from two opposing mechanisms: common knowledge of the benefits that can be obtained through the reduction of transaction costs and the need to address the distribution issues. It is no coincidence that Article 2 of the Treaty of Rome recalls among the EU objectives the "harmonious development of economic activities," a "balanced expansion," and "closer relations between the States." Subsequently, the Treaty of Maastricht called as an objective "the high degree of convergence of economic performance... economic and social cohesion and solidarity among Member States." All this is linked to the legal traditions of continental European countries accustomed to political market intervention being attributed scarce trust. Indeed, the founding states have different regimes, albeit framed in the civil law tradition.

Normative constitutional economics, thus, insists on an evolutionary contractual process that allows the community through a series of experiments to determine whether the constitutional choices correspond to a general interest (they are generally shared) or whether they tend to favor special interests that are not justified in a socially useful outcome. Of fundamental importance here is the selection of constitutional and subconstitutional rules; the former regulate and limit the decision-making process, while the latter relate to specific behavioral choices aimed at solving individual problems.

Accordingly, the difficulties encountered by the EU are evident; in other words, the errors that Vanberg (1999) indicates are linked to the need to ensure consent in the European integration process through intervention policies (sub-constitutional rules).

It should be noted here that the European Economic Community (EEC) Treaty and the Maastricht Treaty refer to the definition of an economic constitution for a market system (dialog notion) and to a series of nonmarket (intervention) policies (contract notion). These intervention policies are explicitly (regional or agricultural) or implicitly (trade or industrial) aimed at creating different national interests.

Clearly, there is some concern that this will lead to some form of rent-seeking behavior, considering that the concept of common interest is itself largely ambiguous and 
often the sum of sector and government interests and the commission's drive to wield more power and influence (Vaubel 1999). The evolution of the intervention processes of European institutions thus characterizes the EU as a community that is constitutionally based on theory (common benefits that are shared because of the creation of an internal market, i.e., what is best for all) and on interests (the need for economic policy interventions to obtain what is mutually acceptable).

It would be an oversimplification to assume that the EU has efficiently fulfilled all the conditions set out above. This is because the EU is the product of considerable political negotiations and the conflict between national and EU interests. Solutions to such conflicts can prove to be very costly for all. For example, the Common Agricultural Policy (CAP) is the result of intense bargaining and has cost the EU dearly. Yet, it has remained central to EU regional integration bargaining over time. Building the single market entailed the costs of compromises such as those based on the CAP. Clearly, these costs must be less than the advantages of creating a single market.

\section{ASEAN and the ASEAN Way}

The formation of the ASEAN internal market can be usefully compared with the equivalent European process insofar as pursuing the same objectives is concerned, in particular, the construction of an internal market but with substantially different processes. This, thus, constitutes an important case study to assess the different forms of integration of European markets when compared with Asian markets.

After all, Asian scholars and politicians have always referred to the substantial difference between the European integration method and that of Asian integration - the so-called ASEAN Way — which rejects the use of supranational solutions that are based on the rule of law in favor of forms of informal and intergovernmental cooperation. The ideas underlying the agreement should, therefore, be sought in neutrality on the basis of regional priority, territorial integrity, national sovereignty, and the principles of non-interference. This explains the search for peaceful solutions to disputes and for nonformality in decision-making (Stubbs 2008) or the notions formally expressed in the Treaty of Amity and Cooperation in Southeast Asia in 1979.

ASEAN has its origins in the mid-60s in the difficult context of international politics 
providing support to institutional ideas and consequently to a structure aimed at ensuring the autonomy and independence of member states. Stubbs (2008) identifies the spread of communism and the Cold War, along with newly acquired independence and fierce nationalism, as the key to understanding the reasons for the birth of the bloc. At the end of the 70s, interest in an economic agreement began to manifest, which was, however, seen more as a tool to ensure the autonomy of member states and as a defense against the spread of communism.

However, the ASEAN Way is also referred to as resulting from the typical cultural traditions in many Asian countries. Jetsche and Rüland (2009) consider the cooperation achieved in ASEAN in the context of these traditions, which, in the institutional isomorphism logic, guides political choices in compliance with what is considered to be appropriate behavior in terms of collective identity (March and Olsen 1989). Jetsche and Rüland (2009) identify the expression of these Hindu historical and cultural roots in the Arthashastra, a treatise based on the assumption that a ruler is surrounded by concentric circles (mandalas) of opponents and allies, with the former identifiable in closer circles, thus underscoring the need to find allies in the farther circles. According to this logic, external relationships tend to become aggressive and expansive, and the authors derive some concrete consequences for regional cooperation policies from this notion: the mandala's cultural roots point to power (and therefore expansion attempts) as the dominant factor of international relations. This explains the need to concentrate power in the central authorities without delegating such power, also to avoid the chaos that would result from power that is too diluted in weak international institutions. Their role, if they exist, can only be to strengthen the central power of states.

The same conclusion can also be reached in another way, i.e., by recalling the concept of Asian values repeatedly invoked by the leading politicians of many Asian countries, such as Lew Kuan Yew, former Prime Minister of Singapore, the first to use it politically, and also key individuals in Malaysia, Japan, South Korea, and Hong Kong. The aforementioned expression has been used to justify a value system that prioritizes economic development and the consequent improvement in standard of living and can, therefore, overshadow individual rights at least until their denial is considered necessary to ensure economic progress. This is opposed to the European context, which, as mentioned earlier, bases the construction of the internal market on an institutional structure that has the defense of individual rights as its first task and again illuminates the reasons behind the poor success of the rule of law in the construction of a regional internal market (Ehr-Soon Tay 2007). 
Adding to these cultural anthropological considerations the observation that, historically, in Asian countries, the ruler held absolute control of the market and that, therefore, no independent class of capitalist merchants existed, it can be deduced that there was a lack of incentives for market legalization. However, legalization was imposed later by Western colonial regimes to protect their interests and was experienced as the source of injustice and political discrimination, helping to understand Jetschke and Rüland's conclusion that the prospect of a regional market built according to the European rule of law logic has never been credible for ASEAN.

Moreover, even traditional economic analysis tends to justify the lack of interest in the construction of an internal market. Krapohl and Fink (2013), analyzing the different paths of regional integration in Europe, Asia, and Africa, note that in analyzing trade flows and levels of industrialization, ASEAN is characterized by an economic structure with high extra-regional interdependence and limited economic asymmetries. This leads to interest in regional integration as a function of the external position: intraregional integration is considered to be particularly interesting because of the positive effects of increased attention of foreign investors rather than the growth of intraregional trade. This is how the ASEAN + 3 process was launched, which led to not only greater institutionalization of relations with key external partners but also greater asymmetry that has likely accentuated the fears of ongoing efforts related to the rule of law.

Conversely, interest in the external component of development requires greater attention to be paid to the indispensable role of the legal order. Indeed, foreign investors have, on numerous occasions, reported the absence of common rules as one of the main difficulties in considering the ASEAN internal market as an opportunity to invest. Extra-regional interests must be considered in analyzing the possibilities of deepening the cooperative project. In other words, the focal point of building an internal market may be found precisely in the common interest toward the outside. However, this assessment is not reflected in reality: Krapohl and Fink (2013), for example, identify the ASEAN Industrialization Cooperation (AICO), an agreement signed in 1996 to facilitate commercial partnerships, as a case in point. In this context, Japan requested consent for the exchange of automotive components between firms located in different ASEAN countries. However, the lack of an enforcement mechanism allowed the same countries to protect their enterprises, disregarding the AICO in favor of national interests.

This same observation has repeatedly been made in subsequent years. In 2015, an Asian Development Bank paper (Menon and Menendez 2015) noted that the most obvious failure of the Asian Economic Community (AEC) scorecard is that there is 
no mechanism to exert pressure or support sanctions when the AEC objectives are not achieved - partly because national reports are confidential and cannot be used to exert pressure. It has also been reported that $38 \%$ of multinational companies operating in Asia believe that the customs processes are not uniform, creating obvious problems for their businesses.

The informal structure of ASEAN and the opposition to building strong and formal institutions and legally binding obligations result from the association's founding values (Rattanasevee 2014), and this means that ASEAN was built in a way that ensured that sovereignty remained firmly in the hands of states. Ewing-Chow and Li-Hsien (2013) summarize this ASEAN political configuration, arguing that its raison d'être is based on realism, the self-interest of individual states or, at most, a type of functionalism based on common interests when they exist. This description would seem to be confirmed by the absence in the official ASEAN documents of not only generic objectives but also clearly stated ones, invoking the metaphor of the blind man who tries to discern through touch what an elephant looks like. This point can be more clearly understood when considering, in the EU case, the importance of a clear definition of the internal market ("market without frontiers" as defined by the Single European Act) for its effective implementation.

ASEAN has always had this at its base when it began to assess the cost effectiveness of the construction of the internal market and a common industrial base. The most recent documents, particularly the ASEAN Charter adopted in 2007, unambiguously included among the ASEAN objectives the creation of a single market and a common manufacturing base. More significantly, the need to legalize the agreement began to emerge.

The 1992 decision to implement an Asian Free Trade Area (AFTA), an Asian Investment Area (AIA), and subsequently the AEC, belongs to this period. Numerous works explain the evolution of these agreements over time; there are also numerous unofficial documents on the substantial failure of efforts to achieve trade cooperation owing to the lack of a clear blueprint that could identify the final objectives and ways to achieve them, as well as the costs and benefits attributable to their integration and distribution among member states. In other words, as Soesastro (2005) claims, it was the inability to consider the need to jointly establish objectives and instruments and avoid the facile criticism of the previous AFTA initiative that had earned it the nickname "Agree First Talk After."

Authoritative statements on the need for legal constraints on the liberalization and 
integration process are aplenty. For example, the Eminent Person Group report (2006) stated "ASEAN's problem is not one of lack of vision, ideas, or action plans. The problem is one of ensuring compliance and effective implementation. ASEAN must have a culture of commitment to honor and implement decisions, agreements, and timelines." Severino, the ASEAN Secretary General had made similar remarks in 2001.

A judgment that sounds very much like a criticism of the traditional principle of nonintervention in national policies, particularly when the group suggested that "ASEAN should have the power to take measures to redress cases of serious breach of ASEAN's objectives, major principles, and commitments to important agreements. Failure to comply with decisions of the dispute settlement mechanisms should be referred to the ASEAN Council. Such measures may include suspension of any of the rights and privileges of membership."

\section{Is the ASEAN Internal Market Achievable?}

In reality, it would seem that in the years following the Eminent Persons Group's opinion, some important steps have been taken toward the legalization of ASEAN. In 2008, the ASEAN Charter was adopted, which was hailed by many as the association's new constitution, but did not proceed beyond announcing the objective. The charter clearly mimics the European institutional lexicon, yet as Jetsche and Murray (2012) note, this does not translate into a real institutional change.

Under these conditions, is the effective implementation of the internal market achievable? This question entails two different problems: is it possible for ASEAN to achieve within the existing institutional framework an internal market that is based on the rule of law but without a centralized structure of rules and their coercion and enforcement mechanisms? Again, if the answer to the first question is no, is a constitutional change possible that would enable supranational governance?

The first question leads to the recent studies of Hadfield and Weingast $(2013,5)$ that demonstrate that an equilibrium legal order without centralized decisions and coercion mechanisms could be envisaged in particular circumstances. "There is an identifiable entity that serves as an authoritative steward of a unique, clear, and non-contradictory normative classification that is prospective and reasonably stable. This classification 
must be public and common knowledge. It must enable ordinary individuals to predict reasonably well the classifications that the system will reach through the use of impersonal, neutral, and independent reasoning to extend generalizable classifications to specific and novel circumstances."

To achieve this, the institution tasked with coordinating the legal order must facilitate the integration of knowledge and ways of reasoning of each individual (state) in a generalized and sufficiently universal way to be able to serve the interests and needs of all of those who play an important role in its decentralized enforcement. Further, individuals (states) must perceive that belonging to such a coordination mechanism increases their wellbeing.

Turning to ASEAN, the question can be answered thus: it is possible to envisage a non-centralized lawful order if an institution can be created that is able to choose from a list of universally recognizable rules of conduct and where the incentive for actors to respect a behavior that the classification considers to be not wrongful is to avoid incurring a penalty. However, the ability to impose a penalty should not necessarily be attributed to this or another centralized institution. Hadfield and Weingast $(2013,8)$ consider this to be "a form of collective punishment whereby delivery of an effective penalty depends on independent and simultaneous decisions made by individual nonofficial actors to punish a wrongdoer."

From this perspective, the functioning of the known mechanisms of decentralized collective punishment (loss of reputation, retaliation, shame, ostracism, or suchlike) leads us to the central question regarding coordination among different countries for a common interpretation of the rules and a common assessment of the need for punishment. The existence of a legal institution that is capable of producing a common classification of the conduct of an individual (state) as wrong or right reduces ambiguity and makes the coordination of collective punishment possible.

Indeed, according to Hadfield and Weingast, the ASEAN experience to date does not seem to meet the requirements. The ASEAN Secretariat cannot be considered to be an authoritative steward, considering that, at most, it can make proposals or informal recommendations and is not regarded as a political but a purely functional organ (Henry 2007). Decisions are made by consensus, which means that negotiations must continue until an agreement is reached, which is often accompanied by high levels of ambiguity.

The instruments for the resolution of disputes are not mandatory though, at least formally; however, when used, they produce final and binding decisions. However, states can negotiate suspension measures with other parties to the litigation, thus not creating 
interpretative certainty. Even more importantly, the decisions of the dispute resolution organ (in practice, a panel of experts appointed from time to time) are absolutely confidential. This leads to the absence of the conditions of openness, transparency, and common knowledge that are necessary for the formation of a legal system. A practice that seems to confirm the interpretation that the weak institutionalization of ASEAN also reflects, together with the cultural origins we first mentioned, a political economy problem, namely, the need to ensure, beyond liberalization measures, the protection of politically important enterprises. This justifies the preference for informal agreements and exhaustive political negotiations as they allow ambiguous compromises and fudging that protect key interests (Jones 2015).

In essence, the lack of a sufficiently strong bureaucracy affects the possibility of having an authoritative steward, while the diverse interests of member states do not allow the creation of punitive coalitions that are able to impose collective sanctions.

In this situation, the possibility of creating an internal market governed by the rule of law is linked to a constitutional change that introduces effective forms of legalization and is constrained by the increasing powers of common institutions - a solution that would seem to be supported by the ASEAN Secretariat and other international institutions, such as the Asian Development Bank ${ }^{2}$. Is this feasible?

Vanberg (2001) indicates that the construction of an economic constitution culminates through trial and error and must enable adaptation to the changes in the environment it operates in, considering the effects that the constitutional choices have on the ability to solve problems or rather on the evolution of the problem-solving capacity. In other words, the efficiency of the constitution is related to the accumulation of experience and knowledge to determine constitutional norms that are able to guide the sub-constitutional choices.

There is, therefore, a link between past institutions, learning, and constitutional change; however, which factors make change possible?

In the table reproduced here, Streeck and Thelen (2005) summarize the debate on institutional changes, where both incremental and discontinuous change processes are analyzed.

\footnotetext{
2 In 2008, in the preamble of the ASEAN economic blueprint, the Heads of State were "Cognisant of the need to have a strengthened institutional framework and a unified legal identity as set forth in the ASEAN Charter by putting in place rules-based systems to realize the establishment of the AEC by 2015".
} 
Table 2. Types of institutional change: processes and results

\begin{tabular}{|c|l|l|l|}
\hline \multirow{2}{*}{ Types of change } & \multicolumn{2}{c|}{ Result of change } \\
\cline { 3 - 4 } & \multicolumn{1}{|c|}{ Continuity } & \multicolumn{1}{c|}{ Discontinuity } \\
\hline \multirow{2}{*}{$\begin{array}{c}\text { Process of } \\
\text { change }\end{array}$} & Incremental & Reproduction by adaptation & Gradual transformation \\
\cline { 2 - 4 } & Abrupt & Survival and reform & $\begin{array}{l}\text { Breakdown and } \\
\text { replacement }\end{array}$ \\
\hline
\end{tabular}

(Source) Streeck and Thelen (2005)

In the case of ASEAN, a complex issue arises because there is no real treaty to change but a series of informal agreements that have modestly affected economic relations between the states and because the actors interested in change (or avoiding it) are manifold, from national governments to economic operators and particularly organized production sectors, which can considerably influence any negotiation.

Building a market with a legal order would imply - according to Mahoney and Thelen (2010) - the displacement of old rules and their replacement with new ones. A change that would normally take the form of discontinuity but which could, according to the two authors, also take the form of an incremental process when the old rules can be put in competition with the new, leaving traders with a choice. Such a choice, however, might be impossible because of the nature of the ASEAN agreement. Further, the displacement formula would require weak veto power vested in states, with an immediate renunciation of national sovereignty - exactly the opposite situation to that favored by ASEAN.

Moreover, a hypothesis of change can be envisaged following Voigt's (1999) proposal indicating constitutional change as resulting from bargaining between different interests, considering that the result of the change itself is the redistribution of benefits derived from the existing constitutional order. In our case, we envisage the formation of a constitutional group, i.e., a group of public and private operators supporting the introduction of a supranational legal order to regulate the ASEAN internal market that is formed by stakeholders who see in the new order an advantage for themselves (mainly export industries, consumers, and operators favoring the entry of foreign direct investment) and who are opposed to stakeholders in favor of maintaining the status quo (i.e., governments and representatives of protected areas). The stronger the first group 
feels, the greater the possibility of starting a negotiation that would eventually lead to a constitutional change.

This is a rather complex hypothesis to verify owing to the difficulty of measuring the bargaining power of participants in the game even if it is seemingly clear that ASEAN governments have greater possibilities than the counterparties and, above all, because it is difficult to measure the utility frontier within which the same parties move. As Voigt identifies, in a constitutional negotiation of this type, the subject of the dispute is not a measurable amount of benefits to redistribute but the identification of rules and procedures that the constitution uses to allocate the costs and benefits of the legal order. As historical experience shows, any theory that is used to support the positions of different parties participating in the negotiation may be proved wrong; therefore, whether the result of the negotiation will be Pareto-optimal is uncertain.

In other words, the conditions for a gradual institutional change do not seem to exist owing to weak institutions, such as those in ASEAN, which are unlikely to set in motion a process of radical change such as that required in this situation and because the distribution of bargaining power among those in favor and against seems tipped in favor of the latter.

The other path studied by constitutional economics is that of change favored by a state of crisis that substantially changes the conditions under which the existing constitutional structure has developed. Streeck and Thelen (2005) consider this possibility as being typical of sudden or abrupt change processes, the result of which can be failure, and subsequently, the return of the preexisting order or its displacement and replacement with a new institutional structure. Scholars who support this hypothesis generally consider that gradual changes are actually adaptive and only serve to ensure the continuity of the previous order.

ASEAN has over time experienced deeper crises that did not, however, create enough stimuli for a radical change of the preference for a regional market order based on the rule of law. Jetschke and Rüland (2009) analyze two major discontinuity crises, the first linked to the end of the Cold War and the second to the Asian financial crisis of 1997 1998, noting that neither case led to the initiation of a serious change in the constitutional foundations of ASEAN integration.

Particularly after the financial crisis, the voices of those who intended to imitate the European model began to be heard. They started adopting the typical terminology of the European integration process such as "economic community" and "single market." This could have paved the way for a localization strategy or, according to Jetschke and 
Rüland, an intermediate effort between inertia, namely, the inability to find solutions to the cooperation problems, particularly through constitutional change, and transformation, i.e., a complete change of ideas at the base of the integration processes. In the case of ASEAN, the latter route would have led to the abandonment of the founding conceptthe ASEAN Way (as summed up in recent times) - in favor of a new approach, which would have been able to provide solutions to the problem of building an internal market based on the rule of law.

The subsequent events demonstrate that if the path of transformation or the displacement of old institutions appears impractical, the only feasible path would be that of localization. Acharya's $(2004,245)$ definition recalled by the authors, "... the active construction through framing, grafting, pruning, and cultural selection of foreign ideas by local actors which results in the former developing significant congruence with local beliefs and practices" leads to speculation on the possibility of localization in ASEAN, eschewing the European experience of mutual recognition or the open method of coordination; attempts have been made in recent years in ASEAN but have yielded nothing but inertia.

However, the problem of internal market building is complex, and the array of rules that can be used to modify the incentives of participants is extremely large. Moreover, even when the participants' interests for changes in the rules are the same, it is rarely possible to predict the consequences of a particular set of rules in a specific setting. These results suggest that the process of choosing new rules requires more experimentation than a top-down mechanism managed by a central planner; "rules developed with considerable input, if not fully their own decision, of the resources users themselves, achieve a higher performance rate than systems where the rules entirely are fully determined by external authorities" (Ostrom 2006).

Evolutionary theory suggests that it is precisely this capacity to create institutions in this way that differentiates successful communities from others. Hayek (1960) anticipates this conclusion in The Constitution of Liberty, "... a group of men can form a society capable of making laws because they already share common beliefs which make discussion and persuasion possible and to which the articulated rules must conform in order to be accepted as legitimate."

In other words, without a minimum level of common values, external institutions that withstand time cannot be established. Paraphrasing Aoki, it could be argued that past and future institutions are mutually linked: institutions created endogenously in the past through complex mechanisms of interconnecting their various domains can become 
exogenous constraints and/or enabling factors for further institutional dynamics. In this sense, "history matters" as well as "institutions matter" (Aoki 2007).

\section{Conclusions}

According to Hadfield and Weingast $(2012,473)$, a market is where "there is an identifiable entity that deliberately supplies a normative classification scheme that designates some actions as 'wrongful,' and actors, as a consequence of the classification scheme, forego wrongful actions to a significant extent." We followed this definition of a market as our benchmark for comparing the construction of the internal market in ASEAN and the EU, in that it intentionally makes no reference to centralized or coercive powers to avoid having to consider the European model in environments differing from the European Community.

In reality, the analysis of the ASEAN single market construction process, which is officially indicated by member states as the objective, has thus far not led to tangible results. It is a situation that can be attributed to the incapacity for constitutional change, which should be remedied by the introduction of a new idea, a new focal point, which is able to find a new balance between different interests. We indicated that a constitution needs to specify the operational criteria of an organization, particularly to resolve the fundamental issues that arise from joint actions, such as the rules governing collective decision-making and distribution problems. The greater the collective action, the greater is the need to find efficient solutions to the decision-making processes and the distribution of jointly produced products. In other words, to date, the ASEAN economic constitution has not met these goals, nor has it played the role of "coordinating device" hypothesized by Hadfield and Weingast.

The prospect of completing the ASEAN internal market is therefore linked to disseminating knowledge among the various governments and economic operators for them to recognize the problem and subsequently achieve a common understanding of both the problem and the solution, thereby recognizing and punishing the defaulters. Integration can only proceed if the loss of the role of national governments in representing national interests can be offset by increased cooperation with other national authorities, such as parliaments, governments, and regional representatives 
of the interests of civil society. To overcome the current constitutional limitations, a clarion call has been sounded for more substantial involvement of political actors from different national and local authorities and representatives of economic operators in the ASEAN institutional framework. In other words, integration can only proceed with democratization.

Thus far, only the first part of this long and complex path seems to have been traversed.

Received 21 November 2016, Revised 20 January 2017, Accepted 26 January 2017

\section{References}

Acharya, Amitav. "How Ideas Spread: Whose Norms Matter? Norm Localization and Institutional Change in Asian Regionalism.” International Organization 58 (2004): 239275.

Aghion, Philippe, Yann Algan, Cahuc Pierre, and Shleifer Andrei, "Regulation and Distrust." Quarterly Journal of Economics 125 (2010), 1015-1049.

Aoki, Masahiko. "Endogenizing Institutions and Institutional Changes." Journal of Institutional Economics 3 (2007): 1-31.

Beckert, Jens. "The Social Order of Markets.” Theory and Society 38 (2009): 245-269.

Boettke, Peter J., Coyne Christopher J., Leeson Peter T., and Sautet F. Frederic. "The New Comparative Political Economy." Review of Austrian Economics, 18 (2005), 281304.

Brennan, Geoffrey and Hamlin, Alan: "Constitutional choice". In The Elgar Companion to Public Choice, edited by William Shughart II and Laura Razzolini (2001): 117-139.

Buchanan, James. "The Domain of Constitutional Economics". Constitutional Political Economy, 1 (1990): 1-18.

Buchanan, James. "Europe as Social Reality". Constitutional Political Economy, 7 (1996): 253-256. 
Craig, Paul. "Constitutions, Constitutionalism and the European Union." European Law Journal 7 (2001): 125-150.

De Burca, Grainne. "The Constitutional Challenge of New Governance in the European Union." European Law Review 11 (2003): 343-364.

Dixit, Avinash, ,Skeath, Susan and Reiley, Davis, "Games of Strategy", W. W. Norton \& Company, (2009).

Djankov, Simeon, Glaeser Edward, La Porta Rafael, Lopez-de-Silanes Florencio, and Shleifer Andrei. "The New Comparative Economics." Journal of Comparative Economics 31 (2003): 595-619.

Duina, Francesco. "Regional Market Building as a Social Process: An Analysis of Cognitive Strategies in NAFTA, the European Union and Mercosur." Economy and Society 33 (2004): 359-389.

Ehr-Soon Tay, A. "Asian Values and the Rule of Law." in The Rule of Law. History, Theory and Criticism, edited by Pietro Costa and Danilo Zolo, Springer (2013).

Ewing-Chow, Michael, and Hsien-Li Tan. "The Role of the Rule of Law in ASEAN Integration." Robert Schuman Centre for Advanced Studies Global Governance Programme-41, European University Institute, Florence (2013).

Furubotn, Eirik G., and Rudolf Richter. "Institutions \& Economic Theory." The University of Michigan Press (2003).

Garrett, Geoffrey. "International Cooperation and Institutional Choice: The European Community's Internal Market.” International Organization 46 (1992): 533-560.

Garrett, Geoffrey, and Barry Weingast. "Ideas, Interests, and Institutions: Constructing the European Community's Internal Market." In Ideas and Foreign Policy, edited by Goldstein Judith and Robert Keohane: 173-206, Cornell University Press (1993).

Glaeser, Edward, and Andrei Shleifer. "The Rise of the Regulatory State." Journal of Economic Literature 41 (2003): 401-425.

Hadfield, Gillian, and Barry Weingast. "What Is Law? A Coordination Model of the Characteristics of Legal Order.” Journal of Legal Analysis 4 (2012): 471-514.

Hadfield, Gillian, and Barry Weingast. "Law without the State: Legal Attributes and the Coordination of Decentralized Collective Punishment." Journal of Law and Courts, 1 
(2013): 3-34.

Hadfield, Gillian, and Barry Weingast. "Constitutions as Coordinating Devices." In Institutions, Property Rights, and Economic Growth. The Legacy of Douglass North, edited by Sebastian Galiani and Itai Sened, 121-150: Cambridge University Press (2014). Hayek, Frederic. "The Constitution of Liberty". University of Chicago Press (1960).

Henry, Laurence. "The ASEAN Way and Community Integration: Two Different Models of Regionalism." European Law Journal 13 (2007): 857-879.

Jetschke, Anja, and Philomena Murray. "Diffusing Regional Integration: The EU and Southeast Asia." West European Politics 35 (2012): 174-191.

Jetschke, Anja, and Jürgend Rüland. "Decoupling Rhetoric and Practice: The Cultural Limits of ASEAN Cooperation." The Pacific Review 22 (2009): 179-203.

Jones, Lee. "Explaining the Failure of the ASEAN Economic Community: The Primacy of Domestic Political Economy." The Pacific Review (2015) doi 10.1080/09512748.2015. 1022593.

Krapohl, Sebastian, and Simon Fink. "Different Paths of Regional Integration: Trade Networks and Regional Institution-Building in Europe, Southeast Asia and Southern Africa." Journal of Common Market Studies 51 (2013): 472-488.

Mahoney, James, and Kathleen Thelen. “A Theory of Gradual Institutional Change.” In Explaining Institutional Change. Ambiguity, Agency and Power, edited by Mahoney, James and Kathleen Thelen, 1-37: Cambridge University Press (2010).

March, James and Johan Olsen “Rediscovering Institutions.” Free Press (1989).

Menon, Jayant, and Anna C. Menendez. "Realizing an ASEAN Economic Community: Progress and Remaining Challenges." ADB Economics Working Paper Series, n. 432 (2015).

Mulligan, Casey B., and Andrei Shleifer. "The Extent of the Market and the Supply of Regulation." Quarterly Journal of Economics 120 (2005): 1445-1474.

Murray, Philomena, and Alex Warleigh-Lack. "Europe-Asia Studies: the Contribution of Comparative Regional Integration." In The Palgrave Handbook of EU-Asia Relations, 108-123: Palgrave Macmillan (2013). 
Ostrom, Elinor. "The Complexity of Rules and how they May Evolve over Time". In Evolution and Design of Institutions, edited by Schubert Christian and von Wangenheim Georg, Routledge (2006).

Pelkmans, Jacques. "Mutual Recognition: Economic and Regulatory Logic in Goods and Services." In Research Handbook on the Economics of European Union Law, edited by Eger Thomas and Hans B. Schäfer, 113-145: Edward Elgar (2012).

Rattanasevee, Pattharapong. "Towards Institutionalised Regionalism: The Role of Institutions and Prospects for Institutionalisation in ASEAN." Springer Plus, http://www. springerplus.com/content/3/1/556 (2014).

Schelling, Thomas C. The Strategy of Conflict, Harvard University Press, Cambridge (1960).

Secretariat, A.S.E.A.N. Report of the Eminent Persons Group on the ASEAN Charter. ASEAN Secretariat, December (2006).

Severino, Rodolfo. The ASEAN Way and the Rule of Law. Address of the ASEAN Secretary-General at the International Law Conference on ASEAN Legal Systems and Regional Integration. Kuala Lumpur (2001).

Soesastro, Hadi. "Accelerating ASEAN Economic Integration: Moving Beyond AFTA." Paper presented at the Second ASEAN Leadership Forum, Kuala Lumpur (2005).

Stone Sweet, Alec, and Thomas L. Brunell. "Constructing a Supranational Constitution: Dispute Resolution and Governance in the European Community." The American Political Science Review 92 (1998): 63-81.

Streeck, Wolfgang, and Kathleen Thelen. "Introduction: Institutional Change in Advanced Political Economies". In Beyond Continuity: Institutional Change in Advanced Political Economies, edited by Streeck Wolfgang and Kathleen Thelen, Oxford University Press, 1-39 (2005).

Streit, Manfred and Mussler, Werner. "The Economic Constitution of the European Community". Constitutional Political Economy, 5, (1994):319-353.

Stubbs, Richard. "The ASEAN Alternative? Ideas, Institutions and the Challenge to 'Global' Governance.” The Pacific Review 21 (2008): 451-468.

Vanberg, Viktor. Rules and Choices in Economics, Routledge (1994). 
Vanberg, Viktor. "Markets and Regulation: On the Contrast between Free-Market Liberalism and Constitutional Liberalism." Constitutional Political Economy 10 (1999): 219-243.

Vanberg .Viktor. "Constitutional Order and Economic Evolution: Competitive and Protectionist Interests in Democratic Society". In Rules and Reason: Perspectives on Constitutional Political Economy, edited by Ram Mudambi, Pietro Navarra and Giuseppe Sobbrio, 33-55: Cambridge University Press (2001).

Vaubel, Roland. "Enforcing Competition Among Governments: Theory and Application to the European Union.” Constitutional Political Economy 10 (1999): 327-338.

Vibert, Frank. "Europe: A Constitution for the Millennium", IEA Hobart Paper 127 (1995).

Voigt, Stefan. Explaining Constitutional Change. A Positive Economics Approach, Edward Elgar (1999).

Weingast, Barry. "The Political Foundations of Democracy and the Rule of Law." The American Political Science Review, 91 (1997): 245-263.

Zolo, Danilo. "The Rule of Law: A Critical Reappraisal." In The rule of Law. History, Theory and Criticism, edited by Paolo Costa and Danilo Zolo, 3-71, Springer (2007). 